\section{Hydrothermal alteration mapping for geochemical exploration in the Zaviyeh 1:100000 sheet, using aster data}

\author{
MARYAM BABAZADEH ${ }^{1}$, SEYEDEH NARGES SADATI ${ }^{1}$ \\ AND AIDA MOHEBI ${ }^{2}$ \\ ${ }^{1}$ University of Mohaghegh Ardabili \\ ${ }^{2}$ Geological Survey and Mineral Exploration of Iran \\ Presenting Author: mary.amaryam1375@gmail.com
}

The study area is located in Zaviyeh 1:100000 sheet which contains parts of the Markazi, Tehran and Qom provinces. From the perspective of geological zoning of Iran, this area is located in a part of the Urmia Dokhtar magmatic belt. The rocks and geological formations in study area are related to the Cenozoic period and older rocks are not seen in this area. Due to the special geological features of the region, there are mineral potentials (metallic and non-metallic) that can be traced by semidetailed explorations. A combined remote sensing techniques and field studies was performed to distinguish and map geometric location of argillic, propylitic and phyllic alterations associated with copper porphyry deposits. In this research color composite ratio images methods applied to Aster data as a tool for mapping alteration associated with porphyry copper deposits. Color composite ratio images are produced by combining three ratio images in blue, green, and red. Figure 1 shows ratios $4 / 5$, $9 / 8,5+7 / 6$ in RGB, respectively. In this image argillic alteration is seen as red color, propylitic alteration is seen as green color and phyllic alteration is seen as blue color. These data provide important information for alteration mapping and mineral exploration in porphyry copper systems.

Fig. 1: Aster ratio image (bands $4 / 5,9 / 8,5+7 / 6$ in RGB)

Refrences:

[1]. Azizi, H., Rsaouli, A. A. \& Babaei, K., 2007- Using swir bands from aster for discrimination of hydrothermal altered minerals in the northwest of Iran (Se-Sanandaj city); a key for exploration of copper and gold mineralization, research journal of applied sciences, 6: 763-768.

[2]Crosta, A. \& De Souza Fliho, C., 2003- Targeting key alteration minerals in epithermal deposits in Patagonia, Argentina, using aster imagery and principal component analysis, international journal of remote sensing, 24: 4233-4240.

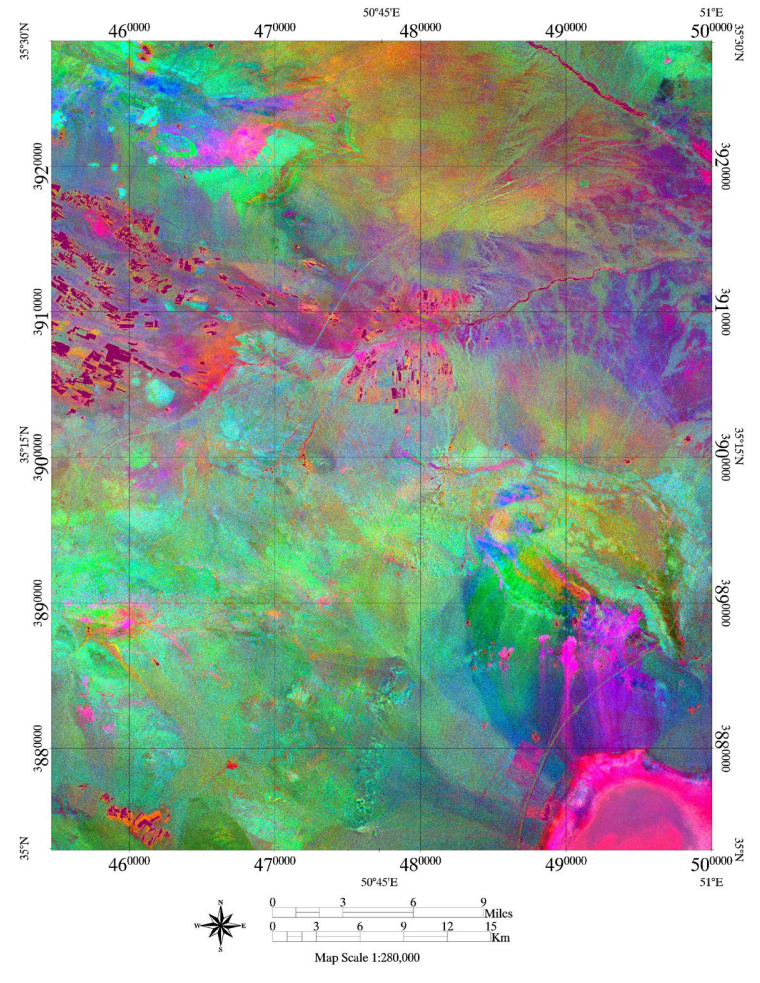

